\title{
DYNAMIC IMPACT OF HEAVY LONG VEHICLES WITH EQUALLY SPACED AXLES ON SHORT-SPAN HIGHWAY BRIDGES
}

\author{
Omar MOHAMMED ${ }^{1 *}$, Arturo GONZÁLEZ ${ }^{2}$, Daniel CANTERO ${ }^{3}$ \\ ${ }^{1,2}$ School of Civil Engineering, University College Dublin, Belfield, Dublin 4, Ireland \\ ${ }^{3}$ Norwegian University of Science and Technology, Richard Birkelands vei, 1A, Trondheim 7491, Norway
}

Received 02 January 2017; accepted 11 December 2017

\begin{abstract}
Extremely large trucks with a weight exceeding the standard require a permit before they are allowed to cross the bridges of a specific route. For the purpose of safety, an escort is often employed to maintain a distance between vehicles and to ensure that the bridge load remains below the allowed maximum. Given that the speed of these large vehicles is quite slow and that the amplitude of vibrations normally declines when the vehicle mass is large, a minor dynamic amplification of the bridge response is expected. However, some of these large trucks have a unique feature characterized by "multiple equally-spaced axles", something that is uncommon in normal vehicle. The application of axle forces at equal intervals dynamically excite bridges to a considerable extent, even at low speeds. These "critical" low speeds are estimated a priori from the axle spacing of the truck and the main frequency of vibration of the bridge. This paper demonstrates that when the "critical" speed is unavoidable, a relatively high dynamic allowance must be added to static calculations before granting a permit to a long heavy vehicle.
\end{abstract}

Keywords: bridge dynamics, critical velocity, dynamic amplification factor (DAF), expansion joint, large trucks, permit vehicles, vehicle bridge interaction (VBI).

\section{Introduction}

Special vehicles above normal legal weight limits have been generally found to govern bridge loading in shortand medium-span bridges (Enright \& O’Brien, 2013). For this reason, there is a considerable amount of research on these traffic-loading scenarios, mostly focused on their static effect on bridges. For example, Casas and Aparicio (2001), and Correia and Branco (2006) analyse the likelihood of large vehicles moving on bridges. They consider various factors that have an impact on the passage of the vehicle over the bridge such as vehicle weight and configuration (i.e., axle loads, axle spacing) and bridge critical length, to provide bridge engineers with an extensive knowledge during the decision-making process of granting a permit. Vigh and Kollar (2007) put forward an algorithm for finding out the bridge safety levels, keeping in view overweight vehicles. The algorithm employs rapid and robust computations that require small amounts of input data like the span and width of the bridge, typekind of superstructure, axle loads and axle spacing of the overweight vehicle. In 2013, Enright and O'Brien (2013) performed Monte Carlo simulation based on wide-rang- ing collections of Weigh-in-Motion (WIM) data from five countries. This data is used to examine the impact of various management policies on the regulation of special permit vehicles. Almost all vehicles weighing more than 100 tons are cranes or low loaders, and those vehicles exceeding 120 tons are low loaders. There are closely spaced axles in both, cranes and low loaders, which typically have around eight or nine heavily loaded axles within an axle group. The length and type of bridge, as well as the load impact being evaluated, determine the intensity of the loading. According to the authors, it is not possible to draw conclusions regarding the effectiveness of regulating the type of vehicles to be issued a permit.

The bridge response to the movement of vehicles is an intricate issue as two structural subsystems (bridge and vehicle) interact with each other through a road surface. The total response has both static and dynamic components. Dynamic Amplification Factor (DAF) is a term widely used in the literature (Brady \& O'Brien, 2006; Mohammed, Cantero, González, \& Al-Sabah, 2014; Rezaiguia, Ouelaa, Laefer, \& Guenfoud, 2015) to quantify the

*Corresponding author. E-mail: omar.sattar@ucdconnect.ie 
interaction between the bridge and vehicle. Dynamic Amplification Factor is defined as the ratio of the maximum total response to the maximum static response during a vehicle crossing, for the load effect of the bridge being examined (i.e., bending moment at mid-span section). This is the definition employed throughout the paper. A review of the factors affecting the dynamic increment with respect to the static component has been recently carried out by (Deng, Yu, Zou, \& Cai, 2014). It has been noted that given a bridge and road profile, there is a DAF-speed pattern associated with a vehicle. It is composed of various peaks and troughs that tend to increase with speed (Brady, O’Brien, \& Žnidarič, 2006; Ding, Hao, Zhu, 2009; Kwasniewski et al., 2006). The traffic laws of each country tend to limit the highest vehicle speed (Enright \& O'Brien, 2013), which is relatively lower for highway bridges as compared to high-speed railways (Yang, Yau, \& Wu, 2004). The vehicle speed is restricted further to permit vehicles due to their weight to ensure safety. Brady and O'Brien (2006) relate DAF peaks due to two moving loads to their spacing and critical speeds. Troughs develop due to destructive interference between both loads. Yang et al. (2004) explain that multiple moving loads can affect the impact factor of the bridge to a large or small extent depending on them being equidistantly spaced (i.e., causing resonance), or at an unequal distance from each other (i.e., cancelling effects). Therefore, Equation (1) defines the resonant speed due to a uniform axle spacing ( $\mathrm{Li} \& \mathrm{Su}, 1999$ ).

$$
v=\frac{f L_{\mathrm{v}}}{n}(n=1,2,3, \ldots),
$$

where $v$ refers to the vehicle speed, $\mathrm{m} / \mathrm{s} ; L_{v}$ refers to the axle spacing of the vehicle, $\mathrm{m} ; f$ - the main natural frequency of the bridge, in $\mathrm{Hz}$.

Shi, Cai, and Chen (2008) adopt Equation (1) to forecast the resonant speeds for the HS20 truck (Section 3 of AASHTO code (2012)) moving across a short bridge of $8 \mathrm{~m}$ length. In this case, the truck has a far lower number of axle loads than a train, but they argue that the multiaxle truckloads are perceived as recurring loads on smaller bridges. While the resonance phenomenon due to configurations made of equally spaced axles has received lots of attention in railway bridges (Cantero, Arvidsson, O'Brien, \& Karoumi, 2015; Cantero \& Karoumi, 2016), the specific problem of quantifying DAF due to permit vehicles with uniform axle spacing has been insufficiently addressed for highway bridges. Cantero, González, and O'Brien (2011) compare DAF due to articulated 5-axle trucks to large cranes at typical highway speeds, but they overlook the resonance effect. This paper fills this gap by analysing the impact of speed, weight, configuration and transverse location of a permit vehicle on the bridge response. For this purpose, simulations are carried out employing VehicleBridge Interaction (VBI) and Finite Element (FE) models. The investigation is focused on short-span bridges where single traffic events involving a permit vehicle may be critical (Enright \& O'Brien, 2013). The influence of road roughness, as well as troughs (or bumps) close to the expansion joints, on DAF is also discussed. Results are compared to a conventional 5-axle truck configuration, commonly found in the road network.

\section{Finite Element Modelling of vehicle-bridge interaction}

A review performed by González (2010) discusses coupled and uncoupled methods employed in VBI simulations. An FE model consisting of 2D plate elements is built with MATLAB sofware to analyse the bridge response. An uncoupled VBI method, based on (Cantero, O'Brien, \& González, 2010), is preferred for computational efficiency. The uncoupled VBI method allows solving the equations of motion of the bridge and those of the vehicle as two subsystems (González, 2010), which are solved by means of a Newmark-Beta direct integration scheme. Initial conditions of displacement, velocity, and acceleration are considered zero in all simulations. The following sub-sections discuss the bridge and vehicle models, the road profile and the interaction algorithm.

\subsection{Bridge model}

A simply supported bridge of $11 \mathrm{~m}$ width (i.e., allowing accommodating a 2-lane carriageway) and $15 \mathrm{~m}$ span length (i.e., allowing a single vehicle event made of a 5-axle truck to fit fully) is modelled as an isotropic thin slab of $0.75 \mathrm{~m}$ depth. Obrien, Keogh, O'Connor (2014) assume a solid slab section typical of short-span bridges following guidelines. The FE slab model is discretised into $0.5 \times 0.5 \mathrm{~m}$ $C 1$ plate elements. There are four Degrees Of Freedom (DOFs) at each node of a $\mathrm{C} 1$ plate element (González, Rowley, \& O'Brien, 2008a): one vertical displacement, one twist and two rotations (in $X$ and $Y$ directions). When compared to the normal Kirchhoff plate element (Reddy, 2002), there is one extra DOF per node in this element to avoid the discontinuity of slope across the edge elements. The moduli of elasticity in the longitudinal and transverse directions are adopted to be $35 \mathrm{GPa}$, and the shear modulus is $14 \mathrm{GPa}$. The material density is $2533 \mathrm{~kg} / \mathrm{m}^{3}$, leading to the $1^{\text {st }}$ frequency of vibration of $5.65 \mathrm{~Hz}$. The damping ratio is adopted to be 0.03 .

\subsection{Vehicle model}

3D models of a long 19-axle vehicle (i.e., simulating a permitted vehicle) and a standard European 5-axle truck are built to compare their influence on DAF. The 19-axle vehicle model (Figure 1) has two significant bodies: the tractor (resting on 3 axles) and trailer (resting on 16 axles), with an overall length of $33.7 \mathrm{~m}$. The selected dimensions are obtained from the Mercedes Benz Trucks/Heavy duty modular trailer and concrete boom rigid truck configuration. Of relevance to this investigation, it is the uniform spacing of $1.5 \mathrm{~m}$ for the axles in the trailer. This $3 \mathrm{D}$ model has 44 DOFs distributed as follows:

- 9 DOFs in the tractor, which record the vertical displacement taking place individually by the six wheels, 
and the bounce displacement, pitch, and roll rotations developing in the body,

- 35 DOFs in the 16-axle trailer to account for each of the wheel displacements and body displacements and rotations.

Tractor and trailer are assumed as two succeeding bodies having the same travelling speed. When no link exists between the tractor and trailer, the towed component in the long-vehicle is defined as a truck without trailer having the same travelling speed as the primary vehicle (Fafard, Bennur, \& Savard, 1997). For all axles, the distance between the left wheel and right wheel is assumed $2 \mathrm{~m}$. Table 1 provides mechanical parameters of the long vehicle. Each wheel has a static weight of $28.31 \mathrm{kN}$ in the $1^{\text {st }}$ axle, $30.07 \mathrm{kN}$ in the $2^{\text {nd }}$ and $3^{\text {rd }}$ axles, and $50.50 \mathrm{kN}$ from the $4^{\text {th }}$ to the $19^{\text {th }}$ axles.

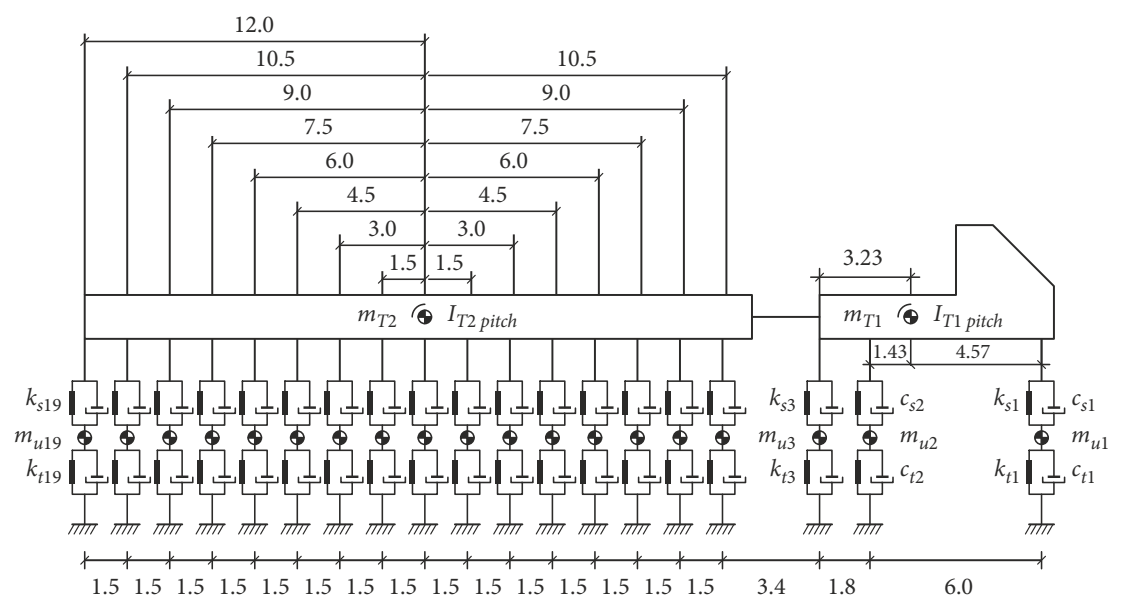

Figure 1. Side view of 19-axle vehicle (all dimensions in meters)

Table 1. Properties of the 19-axle long vehicle ( $R$ and $L$ refer to right and left wheel respectively)

\begin{tabular}{|c|c|c|c|}
\hline Symbol & Property & Value & Units \\
\hline$m_{T 1}$ & Tractor body mass & 15100 & $\mathrm{~kg}$ \\
\hline$m_{T 2}$ & Trailer body mass & 147400 & $\mathrm{~kg}$ \\
\hline$m_{u 1 R}, m_{u 1 L}$ & Mass for each wheel of $1^{\text {st }}$ axle of the tractor & 350 & $\mathrm{~kg}$ \\
\hline$m_{u 2 R}, m_{u 2 L}$ & Mass for each wheel of $2^{\text {nd }}$ axle of the tractor & 550 & $\mathrm{~kg}$ \\
\hline$m_{u 3 R}, m_{u 3 L}$ & Mass for each wheel of $3^{\text {rd }}$ axle of the tractor & 550 & $\mathrm{~kg}$ \\
\hline$m_{u 4-19 R}$ to $m_{u 4-19 R}$ & Mass for each wheel of the trailer & 550 & $\mathrm{~kg}$ \\
\hline$I_{\text {T1 pitch }}$ & Pitch moment of inertia of the tractor body (about $Y$-axis) & $8.8319 \cdot 10^{4}$ & $\mathrm{~kg} \cdot \mathrm{m}^{2}$ \\
\hline$I_{T 1 \text { roll }}$ & Tractor rolling moment of inertia (about $X$-axis) & $6.3 \cdot 10^{3}$ & $\mathrm{~kg} \cdot \mathrm{m}^{2}$ \\
\hline$I_{T 2 \text { pitch }}$ & Pitch moment of inertia of the trailer body(about $Y$-axis) & $7.9988 \cdot 10^{6}$ & $\mathrm{~kg} \cdot \mathrm{m}^{2}$ \\
\hline$I_{T 2 \text { roll }}$ & Trailer rolling moment of inertia (about $X$-axis) & $61.4 \cdot 10^{3}$ & $\mathrm{~kg} \cdot \mathrm{m}^{2}$ \\
\hline$K s_{1 R}, K s_{1 L}$ & Suspension stiffness for each wheel of $1^{\text {st }}$ axle & $0.2 \cdot 10^{6}$ & $\mathrm{~N} \cdot \mathrm{m}^{-1}$ \\
\hline$K s_{2 R}, K s_{2 L}$ & Suspension stiffness for each wheel of $2^{\text {nd }}$ axle & $0.5 \cdot 10^{6}$ & $\mathrm{~N} \cdot \mathrm{m}^{-1}$ \\
\hline$K s_{3 R}, K s_{3 L}$ & Suspension stiffness for each wheel of $3^{\text {rd }}$ axle & $0.5 \cdot 10^{6}$ & $\mathrm{~N} \cdot \mathrm{m}^{-1}$ \\
\hline$K s_{4-19 R}, K s_{4-19 L}$ & Suspension stiffness of each wheel of the trailer axles & $0.5 \cdot 10^{6}$ & $\mathrm{~N} \cdot \mathrm{m}^{-1}$ \\
\hline$C s_{1 R}, C s_{1 L}$ & Suspension damping for each wheel of $1^{\text {st }}$ axle & $0.5 \cdot 10^{4}$ & $\mathrm{Ns} \cdot \mathrm{m}^{-1}$ \\
\hline$C s_{2 R}, C s_{2 L}$ & Suspension damping for each wheel of $2^{\text {nd }}$ axle & $1 \cdot 10^{4}$ & $\mathrm{Ns} \cdot \mathrm{m}^{-1}$ \\
\hline$C s_{3 R}, C s_{3 L}$ & Suspension damping for each wheel of $3^{\text {rd }}$ axle & $1 \cdot 10^{4}$ & $\mathrm{Ns} \cdot \mathrm{m}^{-1}$ \\
\hline$C s_{4-19 R}, C s_{4-19 L}$ & Suspension damping of each wheel of the trailer axles & $1 \cdot 10^{4}$ & $\mathrm{Ns} \cdot \mathrm{m}^{-1}$ \\
\hline$K t_{1 R}, K t_{1 L}$ & Tyre stiffness for each wheel of $1^{\text {st }}$ axle & $0.875 \cdot 10^{6}$ & $\mathrm{~N} \cdot \mathrm{m}^{-1}$ \\
\hline$K t_{2 R}, K t_{2 L}$ & Tyre stiffness for each wheel of $2^{\text {nd }}$ axle & $1.75 \cdot 10^{6}$ & $\mathrm{~N} \cdot \mathrm{m}^{-1}$ \\
\hline$K t_{3 R}, K t_{3 L}$ & Tyre stiffness for each wheel of $3^{\text {rd }}$ axle & $1.75 \cdot 10^{6}$ & $\mathrm{~N} \cdot \mathrm{m}^{-1}$ \\
\hline$K t_{4-19 R}, K t_{4-19 L}$ & Tyre stiffness for each wheel of the trailer axles & $1.75 \cdot 10^{6}$ & $\mathrm{~N} \cdot \mathrm{m}^{-1}$ \\
\hline$C t_{1 R}, C t_{1 L}$ & Tyre damping for each wheel of $1^{\text {st }}$ axle & $1.5 \cdot 10^{3}$ & $\mathrm{Ns} \cdot \mathrm{m}^{-1}$ \\
\hline$C t_{2 R}, C t_{2 L}$ & Tyre damping for each wheel of $2^{\text {nd }}$ axle & $2.5 \cdot 10^{3}$ & $\mathrm{Ns} \cdot \mathrm{m}^{-1}$ \\
\hline$C t_{3 R}, C t_{3 L}$ & Tyre damping for each wheel of $3^{\text {rd }}$ axle & $2.5 \cdot 10^{3}$ & $\mathrm{Ns} \cdot \mathrm{m}^{-1}$ \\
\hline$C t_{4-19 R}, C t_{4-19 L}$ & Tyre damping for each wheel of the trailer axles & $2.5 \cdot 10^{3}$ & $\mathrm{Ns} \cdot \mathrm{m}^{-1}$ \\
\hline
\end{tabular}


a) side view

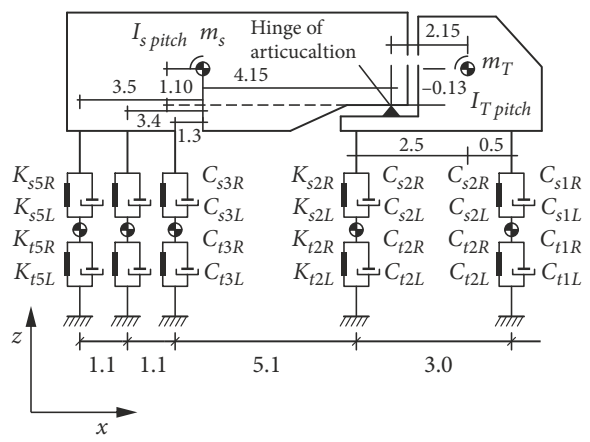

b) back view



Figure 2. General vehicle model sketch

(all dimensions in meters)

Figure 2 shows the 5-axle tractor-semitrailer model that is composed of two main sub-structures, tractor, and semitrailer depicted as grouped masses (Cantero et al., 2010). The model has 15 DOFs in the form of wheel hop displacements (by every of the 10 un-sprung masses of wheel), tractor bounce displacement, tractor pitch rotation, tractor rolling rotation, semi-trailer pitch rotation, and semi-trailer rolling rotation. Besides the geometry, number, and weight of axles, the articulation hinge in the 5 -axle tractor-semitrailer is another feature that distinguishes it from the 19-axle vehicle in Figure 1.

Table 2 gives the mechanical properties of the vehicle. The static wheel weights are $24.94 \mathrm{kN}, 54.39 \mathrm{kN}, 39.00 \mathrm{kN}$, $39.02 \mathrm{kN}$ and $39.02 \mathrm{kN}$ for vehicle axles 1 to 5 respectively based on the distribution of gross vehicle weight proposed by (González, O’Brien, Cantero, Li, Dowling, \& Žnidarič, 2010). The mechanical parameters in Tables 1 and 2 are based on a range of values proposed in the literature (Fu \&

Cebon, 2002; Harris, O’Brien, \& González, 2007; Kirkegaard, Nielsen, \& Enevoldsen, 1997; Wong, 2008), including publications dealing with large vehicles (Cantero et al., 2011; Lehtonen, Kaijalainen, Pirjola, \& Juhala, 2006; Li, 2005).

Following a modal analysis, pitching and rolling body frequencies fall within $1.50 \mathrm{~Hz}$ to $4.50 \mathrm{~Hz}$ and axle hopping frequencies within $9 \mathrm{~Hz}$ to $16 \mathrm{~Hz}$ in agreement with the range published by Cebon (1999). In the case of the permit vehicle associated with Table 1, there are three main modes of vibration in the tractor body: bouncing at $1.59 \mathrm{~Hz}$, pitching at $2.22 \mathrm{~Hz}$ and rolling at $2.88 \mathrm{~Hz}$. There are also three main modes of vibration in the trailer body: bouncing at $1.39 \mathrm{~Hz}$, pitching at $1.79 \mathrm{~Hz}$ and rolling at $2.46 \mathrm{~Hz}$. Wheel hop frequencies of $8.82 \mathrm{~Hz}$ and $10.20 \mathrm{~Hz}$ are found for the first axle and the remaining axles respectively. In the case of the 5-axle truck associated to Table 2, the body masses have bouncing frequencies of $1.49 \mathrm{~Hz}$ for the tractor, pitching frequencies of $2.30 \mathrm{~Hz}$ for the tractor and $1.49 \mathrm{~Hz}$ for the semitrailer, and rolling frequencies of $3.01 \mathrm{~Hz}$ for the tractor and $1.59 \mathrm{~Hz}$ for the semitrailer. Axle hop frequencies of $8.96 \mathrm{~Hz}, 10.70 \mathrm{~Hz}$, and $11.60 \mathrm{~Hz}$ are found for the first axle, second axle, and rear tridem respectively.

\subsection{Road profile}

\subsubsection{Generation of road carpet}

It is possible to create artificial road profiles through a stochastic process based on the power spectral density of vertical displacements combined with the inverse fast Fourier transform technique explained by Cebon and Newland (1983), by ISO 8608:1995 Mechanical Vibration-Road

Table 2. Properties of the 5-axle truck model ( $R$ and $L$ refer to right and left wheel respectively)

\begin{tabular}{|l|l|c|c|}
\hline \multicolumn{1}{|c|}{ Symbol } & \multicolumn{1}{|c|}{ Property } & Value & Units \\
\hline$m_{T}$ & Tractor body mass & 4500 & $\mathrm{~kg}$ \\
\hline$m_{s}$ & Semi-trailer body mass & 31450 & $\mathrm{~kg}$ \\
\hline$m_{u 1}$ & Tractor front axle & 1000 & $\mathrm{~kg}$ \\
\hline $\mathrm{m}_{\mathrm{u} 2}$ & Tractor rear axle & 1100 & $\mathrm{~kg}$ \\
\hline$m_{u 3}$ to $m_{u 5}$ & The mass for each axle of the Semitrailer & 4875 & $\mathrm{~kg}$ \\
\hline$I_{T \text { pitch }}$ & Tractor pitch moment of inertia (about $Y$-axis) & 3000 & $\mathrm{~kg} \cdot \mathrm{m}^{2}$ \\
\hline$I_{T \text { roll }}$ & Tractor rolling moment of inertia (about $X$-axis) & $\mathrm{kg} \cdot \mathrm{m}^{2}$ \\
\hline$I_{s p i t c h}$ & Semi-trailer pitch moment of inertia (about $Y$-axis) & $\mathrm{kg} \cdot \mathrm{m}^{2}$ \\
\hline$I_{s \text { roll }}$ & Semi-trailer rolling moment of inertia (about $X$-axis) & 21000 & $\mathrm{~kg} \cdot \mathrm{m}^{2}$ \\
\hline$K s_{1 R}, K s_{1 L}$ & Suspension stiffness of tractor front axle & $200 \cdot 10^{3}$ & $\mathrm{~N} \cdot \mathrm{m}^{-1}$ \\
\hline$K s_{2 R}, K s_{2 L}$ & Suspension stiffness of tractor rear axle & $500 \cdot 10^{3}$ & $\mathrm{~N} \cdot \mathrm{m}^{-1}$ \\
\hline$K s_{3-5 R}, K s_{3-5 L}$ & Suspension stiffness of each of the semitrailer axles & $500 \cdot 10^{3}$ & $\mathrm{~N} \cdot \mathrm{m}^{-1}$ \\
\hline$C s_{1-5 R}, C s_{1-5 L}$ & Axles suspension damping & $5 \cdot 10^{3}$ & $\mathrm{Ns} \cdot \mathrm{m}^{-1}$ \\
\hline$K_{t 1 R}, K_{t 1 L}$ & Tyre stiffness of tractor front axle & $875 \cdot 10^{3}$ & $\mathrm{~N} \cdot \mathrm{m}^{-1}$ \\
\hline$K_{t 2 R}, K_{t 2 L}$ & Tyre stiffness of tractor rear axle & $1750 \cdot 10^{3}$ & $\mathrm{~N} \cdot \mathrm{m}^{-1}$ \\
\hline$K_{t 3-5 R}, K_{t 3-5 L}$ & Tyre stiffness of each of the semitrailer axles & $1750 \cdot 10^{3}$ & $\mathrm{~N} \cdot \mathrm{m}^{-1}$ \\
\hline$C_{t 1-5 R}, C_{t 1-5 L}$ & Axles tyre viscous damping & $3 \cdot 10^{3}$ & $\mathrm{Ns} \cdot \mathrm{m}^{-1}$ \\
\hline
\end{tabular}




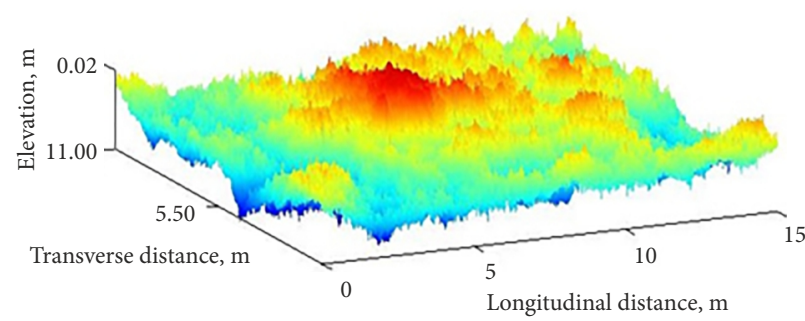

Figure 3. Bridge surface based on the class B road profile

Roughness Surfaces. Fifteen random carpets have been generated for ISO 8608:1995 road class A (very good) with a geometrical spatial means of $16 \cdot 10^{-6} \mathrm{~m}^{3} /$ cycle and for ISO 8608:1995 road class B (good) with a geometrical spatial means of $16 \cdot 10^{-6} \mathrm{~m}^{3} /$ cycle An average moving filter is applied to the randomly generated road profile heights. The filter has a span of $0.24 \mathrm{~m}$ to replicate the short wavelength disturbances brought about by the contact patch of the tyre (Harris et al., 2007; Sayers \& Karamihas, 1996). An example of class B road carpet located on the bridge surface is represented in Figure 3. A $100 \mathrm{~m}$ approach is added before the bridge to produce realistic initial dynamic equilibrium conditions of the vehicle prior to entering the bridge.

\subsubsection{Trough near expansion joints}

Troughs are likely to develop close to the expansion joints. When vehicles travel over troughs, an initial bounce may lead to high impact forces. Although this initial bounce of the vehicle will damp out with time, a high initial vibration is also injected to the bridge deck when the vehicle is close to the bridge support due to the significant kinetic energy accumulated in the vehicle (Moghimi \& Ronagh, 2008). Here, the troughs at the expansion joints are placed at a distance of $0.5 \mathrm{~m}$ from the supports of the bridge. The trough is modelled with a sinusoidal shape of $100 \mathrm{~cm}$ length in agreement with Kim, Kawatani, and Kwon (2007). The trough height is defined by a probabilistic normal distribution with a mean value of $20.4 \mathrm{~mm}$ and a standard deviation of $7.0 \mathrm{~mm}$, following a national survey conducted on roadway bridges in Japan (Honda, Kajikawa, \& Kobori, 1982). Fifteen troughs heights are obtained for each expansion joint at both ends of the bridge. These troughs are added to the 30 road profiles carpets (15 profiles of class A and 15 profiles of class B) described in Section 1.3.1. Figures $4 \mathrm{a}$ and $4 \mathrm{~b}$ show one of the troughs and the result of combining the two troughs with a class $B$ road profile respectively.

\subsection{Vehicle-Bridge Interaction algorithm}

Equations (2)-(3) give the equations of motion of vehicle and bridge respectively.

$$
\begin{aligned}
& M_{v} \ddot{w}_{v}+C_{v} \dot{w}_{v}+K_{v} w_{v}=f_{v}, \\
& M_{b} \ddot{w}_{b}+C_{b} \dot{w}_{b}+K_{b} w_{b}=f_{b}
\end{aligned}
$$

where $M_{v}, C_{v}$, and $K_{v}$ are global mass, damping and stiff- a) isolated trough

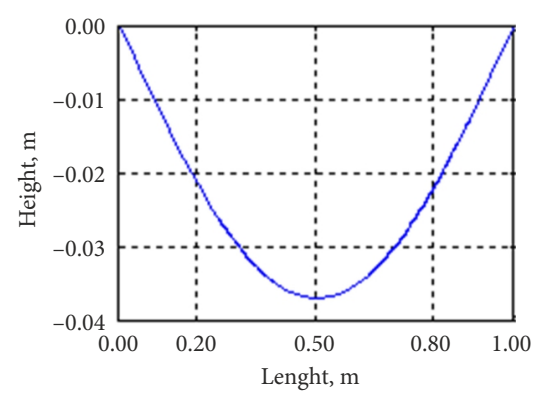

b) two troughs combined with a class B profile

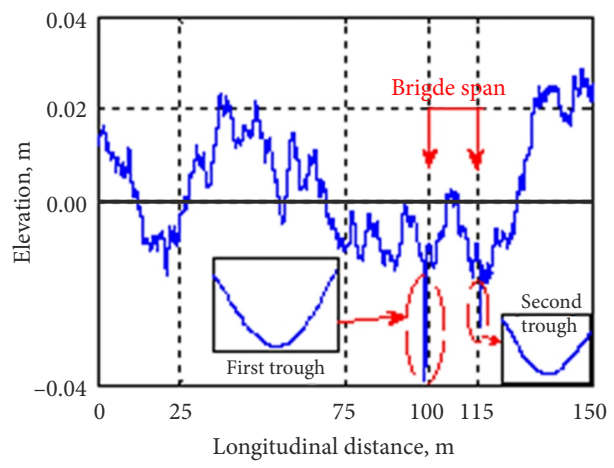

Figure 4. Trough and road profile with troughs

ness matrices of the vehicle respectively; $\ddot{w}_{v}, \dot{w}_{v}$ and $w_{v}$ are the vectors corresponding to nodal accelerations, nodal velocities and nodal displacements.

Cantero et al. (2010) and González (2010) explain how to form these matrixes from assembling mass, spring and damping elementary matrixes into a multi-body dynamics system. $f_{v}$ is a vector containing the time-varying forces imposed on the DOFs of vehicles.

$$
M_{b} \ddot{w}_{b}+C_{b} \dot{w}_{b}+K_{b} w_{b}=f_{b},
$$

where $M_{b}, C_{b}$, and $K_{b}$ - global mass, damping, and stiffness matrices respectively of the plate model; $\ddot{w}_{b}, \dot{w}_{b}$ and $w_{b}$ - vectors containing nodal accelerations, velocities and displacements; $f_{b}$ - the vector of external forces applied to the DOFs of the bridge.

An iterative process is implemented to ensure geometric compatibility between the position of the vehicle wheels and the displacement of the points in the bridge in contact with the wheels. For this purpose, Equation (3) is initially used to calculate $f_{v}$ at the DOFs of the vehicle from the road excitation (i.e., the bridge is disregarded for this initial calculation). This equation is solved via application of the Newmark-Beta direct integration method with a time increment of $0.002 \mathrm{~s}$ and values for the integration constants of delta $=0.5$ and beta $=0.25$. Next, the forces at the DOFs in contact with the bridge or wheel forces (contained in $f_{v}$ ) are converted to equivalent forces acting on the bridge nodes $\left(f_{b}\right)$ using Equation (4).

$$
f_{b}=[L]_{n \times n f} f_{v},
$$


where $[L]$ is an $n \times n_{f}$ time, varying location matrix, which relates the $n_{f}$ wheel forces to equivalent forces acting on the $n$ DOFs of the bridge model.

Full details about this matrix are available in (Mohammed \& González, 2017). The vector $f_{b}$ is then employed in Equation (2) to calculate bridge displacements $\left(w_{b}\right)$ using the same Newmark-Beta integration scheme. These displacements are added to the road profile to recalculate the vehicle forces $f_{v}$ in the $2^{\text {nd }}$ iteration and the process is repeated until the variation among the bridge deflections in two consecutive iterations is inferior to $2 \%$ of the highest bridge deflection. Once the latter is achieved, the forces of the vehicle are positioned at different coordinates on the bridge and the iterative process is repeated for the next time step. The equations in this procedure are solved using MATLAB as further described by (Cantero et al., 2011). The algorithm has been validated against alternative VBI approaches (González, Rattigan, O'Brien, \& Caprani, 2008b) and experimental data (González et al., 2010; Rowley, O’Brien, González, \& Znidaric, 2009).

\section{Estimation of DAF-speed pattern using a vehicle model consisting of moving point loads}

Here, DAF is defined as the ratio of maximum total (static + dynamic) Bending Moment (BM) to maximum static component at the mid-span section of the bridge because of a vehicle crossing. DAF versus speed patterns are, bridge- and road-specific and they allow identifying the presence of critical speeds that cause a relatively higher dynamic response of the bridge. This section carries out a preliminary planar analysis where the bridge is modelled as a beam with the properties of the plate defined in Section 1.1. The vehicle is modelled using point loads to analyse the influence of general bridge characteristics and vehicle configuration on DAF in isolation from other factors such as road profile and vehicle dynamics. In the absence of a road profile (or "very good" road profiles), DAF-speed patterns have a smooth shape made of troughs and peaks located at critical speeds. The DAF-speed pattern for the $15 \mathrm{~m}$ beam bridge model under investigation due to a point load is shown in Figure 5a. The speed of the point load is varied from $10 \mathrm{~km} / \mathrm{h}$ to $122 \mathrm{~km} / \mathrm{h}$ (with a speed increment of $1 \mathrm{~km} / \mathrm{h}$ ). This figure is in agreement with Brady et al. (2006), who analyse the single point load case and identify combinations of vehicle speeds, bridge span lengths and bridge frequencies causing highest dynamic amplifications. They define a dimensionless load frequency parameter as the ratio of vehicular "frequency" (i.e., vehicle speed divided by bridge length) to first frequency of vibration of the bridge. It is possible to change the horizontal axis of Figure 5a from speed to a nondimensional quantity of frequency ratios, which would make the graph applicable to any speed of the point load, bridge length or bridge frequency value. González et al. (2010) retrieve patterns of DAF for multiple point wheels crossing the bridge 3D model. They show that it is possible to find DAF-speed patterns by means of simple point load models, in models and simulations of greater complexity than a beam model, as well as in field trials. The number of axles, their spacing and maximum weights are static mechanical parameters that are easily found about the permit truck, making it possible to derive a DAF-speed pattern for a specific bridge. Figure $5 \mathrm{~b}$ describes the DAFspeed pattern for the planar long vehicle at speeds from $10 \mathrm{~km} / \mathrm{h}$ to $122 \mathrm{~km} / \mathrm{h}$ (with a speed increment of $1 \mathrm{~km} / \mathrm{h}$ ). This graph has been obtained from the response of the beam to a long vehicle model consisting of 19-point loads (one per axle) of value equal to the static axle weights and separated by the axle spacing defined in Section 1.2. There is one noticeable difference when compared to Figure 5(a): peak DAF values are generally smaller in Figure 5b, except for a sharp peak occurring at a relatively low critical speed of $30.24 \mathrm{~km} / \mathrm{h}$ because of constructive interference between axle spacing, speed and main frequency of vibration of the bridge. Using $1.5 \mathrm{~m}$ for the equidistant spacing of trailer axles, Equation (1) gives a critical speed of $30.53 \mathrm{~km} / \mathrm{h}$, approximately the value in the figure except for inaccuracies derived from the discretization level. This low critical speed leads to a maximum DAF value of 1.066.

Figure 6 shows the static and total bending moments at mid-span crossed by the long-vehicle at the critical speed of $30.24 \mathrm{~km} / \mathrm{h}$. Assuming a linear dynamic problem, the contribution of each axle is superposed to obtain

b) 19 moving point loads

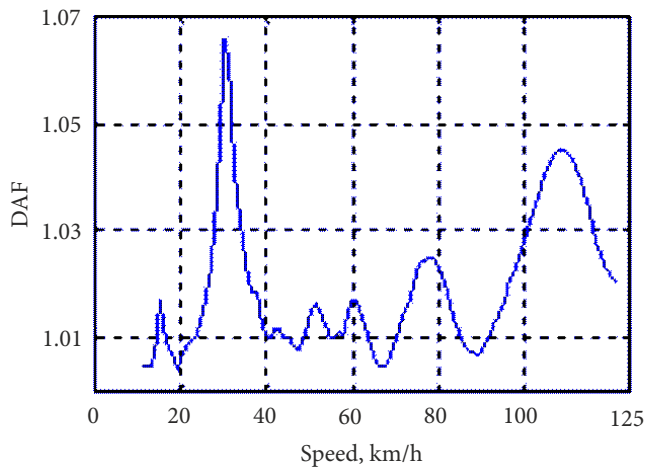

Figure 5. DAF-speed pattern due to 


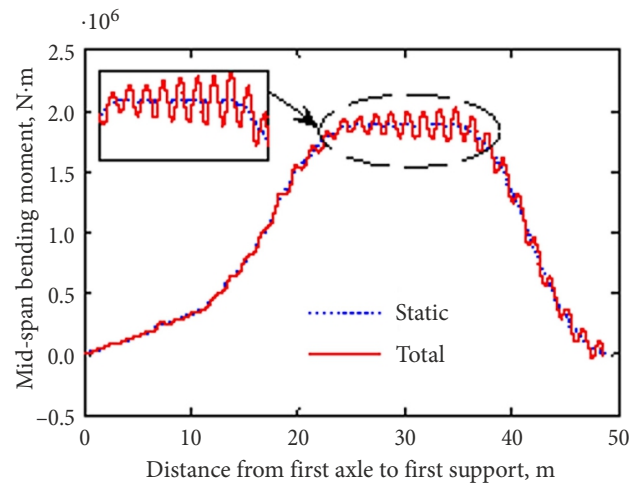

Figure 6. Maximum total and static component of bending moment at mid-span versus location of the first axle

the total response. The individual responses are separated here to understand why dynamic amplification occurs. Figures $7 \mathrm{a}$ and $8 \mathrm{a}$ depict these individual contributions for $30.24 \mathrm{~km} / \mathrm{h}$ and $39.96 \mathrm{~km} / \mathrm{h}$ respectively. According to Figure $7 \mathrm{~b}$, the contribution of each axle to the bending moment reaches the highest stage simultaneously, at $30.24 \mathrm{~km} / \mathrm{h}$. However, at $39.96 \mathrm{~km} / \mathrm{h}$, the contributed features interfere with each other (Figure $8 \mathrm{~b}$ ) leading to a lower DAF of 1.01 compared to 1.066 for $30.24 \mathrm{~km} / \mathrm{h}$.

This dynamic amplification is now explained by applying 38-point moving loads (19 point loads at each side), representing static wheel weights, to the $2 \mathrm{D}$ plate bridge model defined in Section 1.1. The path of the gravity-centre of the vehicle is employed to define its location on the bridge. The gravity-centre of the vehicle is driven centred in one lane (i.e., wheel paths within an axle at $0.75 \mathrm{~m}$ and $2.75 \mathrm{~m}$ from bridge centreline) as shown in Figure 9a. The model has 23 and 31 nodes in transverse (Section A-A in Figure 9b) and longitudinal (Section B-B in Figure 9c) directions respectively. A nodal DAF of bending moment is obtained for each of the twenty-three nodes at the midspan section (set apart by $0.5 \mathrm{~m}$ and labelled 1 to 23 in Figure $9 b)$.

It must be noted that maximum DAF through section A-A (Figure 9b) will typically take place at a different node than the one corresponding to the maximum total bending moment. Therefore, the values of maximum DAF and total bending moment are attained, together with their location. In this scenario, a highest nodal DAF of 1.15 is found for a total bending moment of $159.08 \mathrm{kNm}$ in node 1 and a speed of $30.24 \mathrm{~km} / \mathrm{h}$ (Figure 10a). The highest static bending moment is $204.23 \mathrm{kNm}$ and the maximum total bending moment is $225.083 \mathrm{kN} / \mathrm{m}$. Both taking place at node 23 (Nodal DAF $=1.102)$ at the critical speed of $30.24 \mathrm{~km} / \mathrm{h}$. Nodal DAFs of 1.076 (node 18) and 1.08 (node 13) corresponding to total bending moments of $215.03 \mathrm{kNm}$ and $199.21 \mathrm{kNm}$ respectively are found below the paths of the right and left wheel respectively at the critical speed.

a) moment contribution by each axle

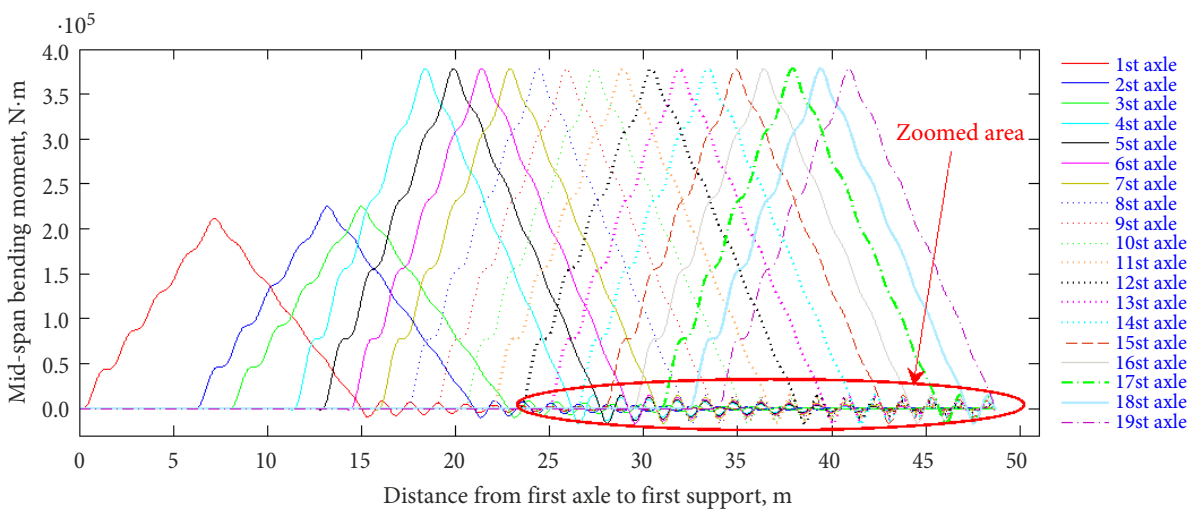

b) zoomed area from (a)

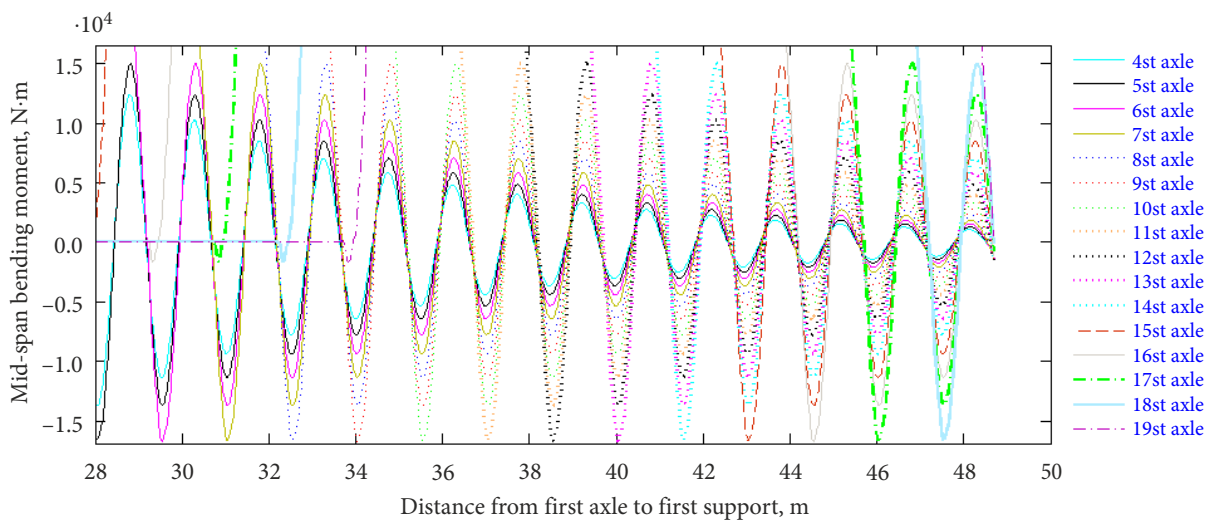

Figure 7. Individual contributions of each axle to total bending moment at $30.24 \mathrm{~km} / \mathrm{h}$ 
a) moment contribution by each axle

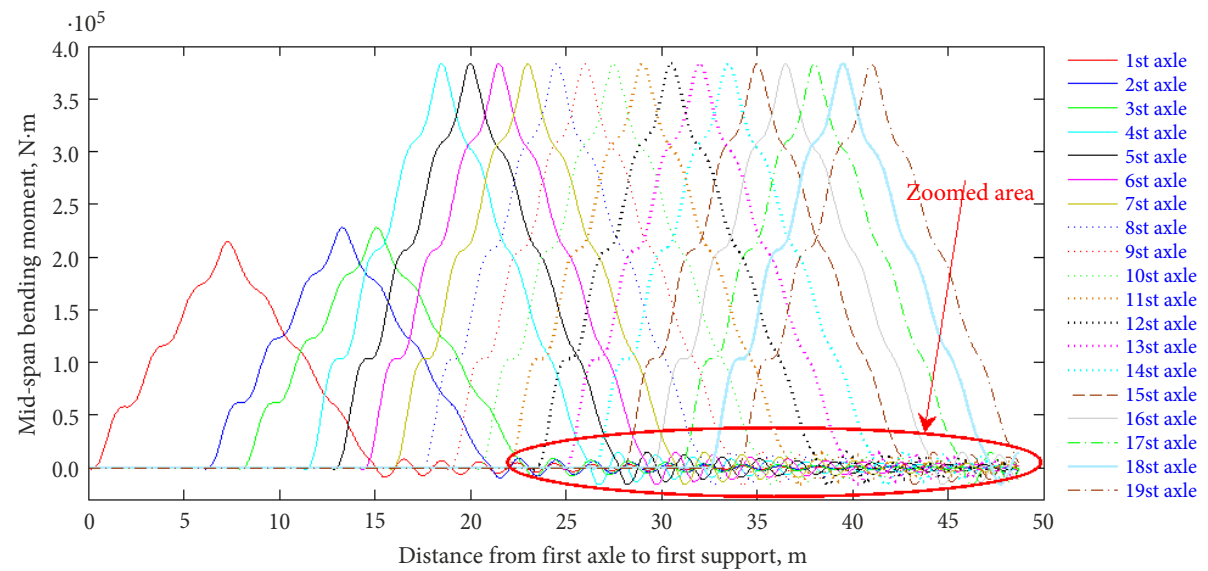

b) zoomed area from (a)

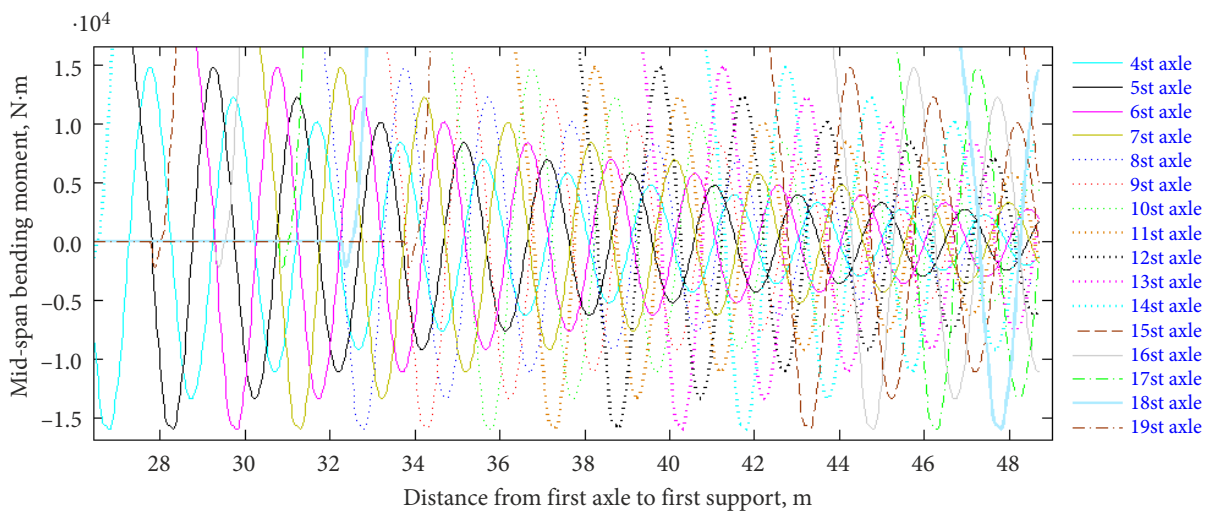

Figure 8. Individual contributions of each axle to total bending moment at $39.96 \mathrm{~km} / \mathrm{h}$

a) plan view showing the travelling path of the centre of gravity of the vehicle (-.-) and wheel paths when driving over one lane (----)

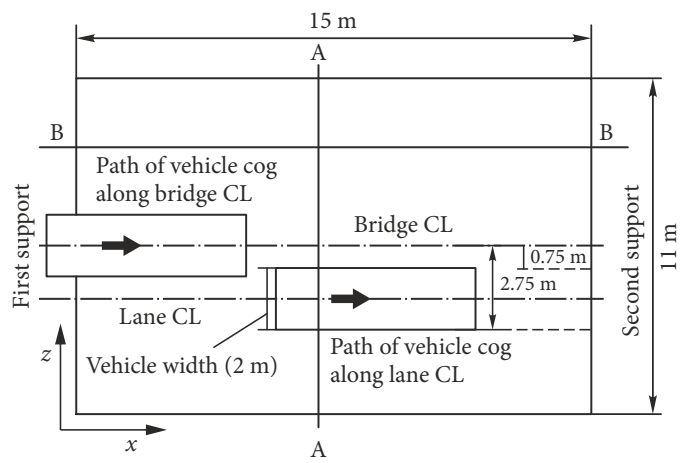

c) side view (Section B-B)

including model nodes b) mid-span cross section (section A-A) including model nodes

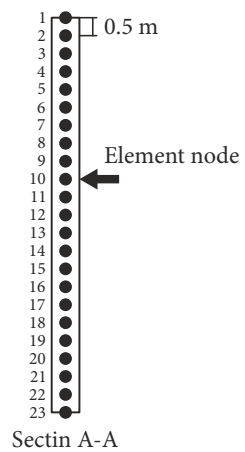

Figure 9. Plate bridge model 
a) nodal DAFs

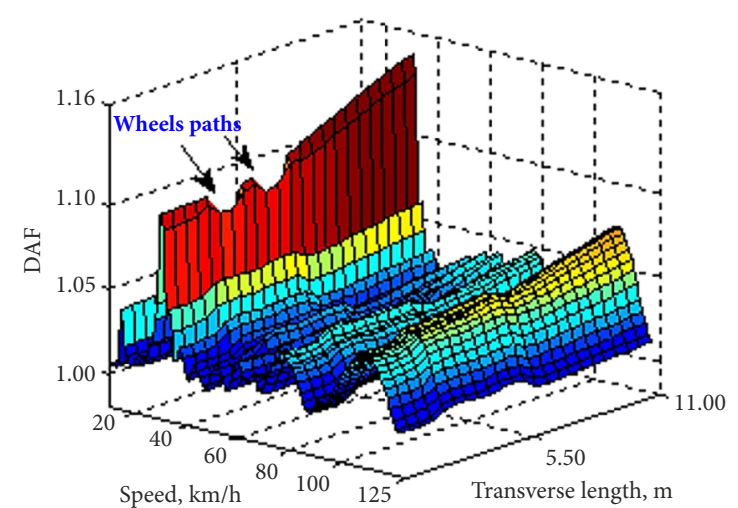

b) global DAFs

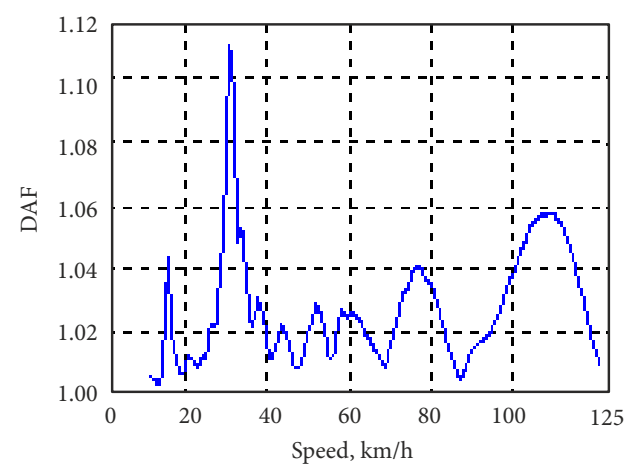

Figure 10. DAF-speed pattern for plate model due to a series of 38 moving point loads travelling with an eccentricity with respect to the bridge centreline

The sum of maximum total response for all 23 nodes is divided by the sum of the maximum static components for those 23 nodes to obtain a global (i.e., averaged) DAF for the mid-span section. The highest global DAF value is 1.11 (Figure 10b). There are differences between the DAF obtained in the beam (Figures 5-8) and plate (Figure 10) models due to the impact of eccentricity of the load and other 3D considerations, but as expected, Equation (1) successfully predicts the critical speed of the long vehicle in both models.

\section{Impact of road surface on DAF-speed pattern}

While the simple model of point loads employed in Section 2 is useful to understand why DAF peaks occur at a relatively low critical speed for a long vehicle, the values of DAF may be unrealistic for a rough profile. For this reason, the next sub-sections take into account road roughness and vehicle dynamics to quantify the true impact of this resonance effect on the DAF of a plate bridge model.

\subsection{Influence of road roughness on DAF}

The mean and standard deviation of DAF values because of the long vehicle moving from $10 \mathrm{~km} / \mathrm{h}$ to $122 \mathrm{~km} / \mathrm{h}$

a) mean DAF

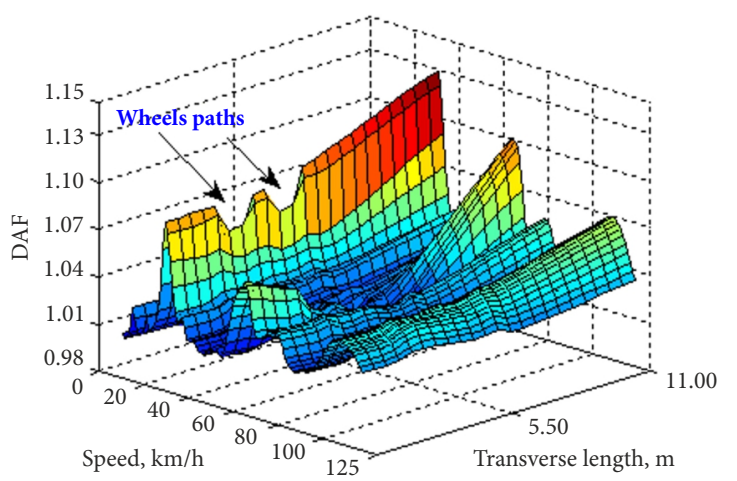

(with a $1 \mathrm{~km} / \mathrm{h}$ increment) over the fifteen class A profiles are shown in Figure 11. The highest DAF of 1.13 (with standard deviation 0.044) occurs at node 1 (Figure $9 \mathrm{~b}$ ) for a total bending moment of $156.57 \mathrm{kNm}$ and the critical speed of $30.24 \mathrm{~km} / \mathrm{h}$ signalled in former sections. The position of the maximum static bending moment $(204.23 \mathrm{kNm})$ is node 23 , where the maximum total bending moment is $222.15 \mathrm{kNm}$ and DAF is equal to 1.087 (standard deviation of 0.036) at the critical speed. DAFs of 1.063 (node 18) and 1.065 (node 13) are smaller under the wheel paths than at other nodes of the mid-span section at the critical speed due to the relatively larger static component of the response (Figure 11a). The latter corresponds to total bending moment values of $212.47 \mathrm{kNm}$ and $196.48 \mathrm{kNm}$ under the right and left wheels respectively.

DAF values rise when the road profile worsens and becomes bumpier, although similar DAF-speed patterns are observed for class $B$ road profiles. The highest DAF value of 1.2 (with 0.07 standard deviation) develops in a class B for $30.24 \mathrm{~km} / \mathrm{h}$. The latter corresponds to a total bending moment of $166.31 \mathrm{kNm}$ at node 1 . The maximum total bending moment is $229.90 \mathrm{kNm}$ (again at $30.24 \mathrm{~km} / \mathrm{h}$ ) and maximum static bending moment of $204.23 \mathrm{kNm}$ take place at the same node $23(\mathrm{DAF}=1.125$ with a standard deviation of 0.065).

b) standard deviation

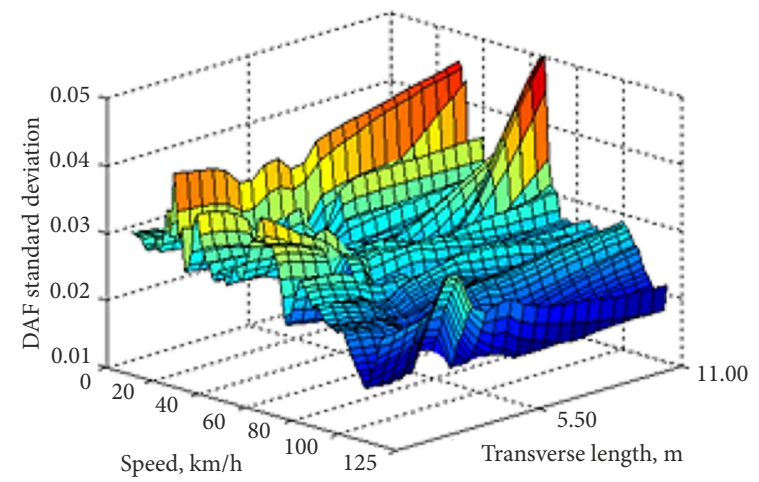

Figure 11. DAF-speed for plate model due to long vehicle on class A profile 
a) mean DAF

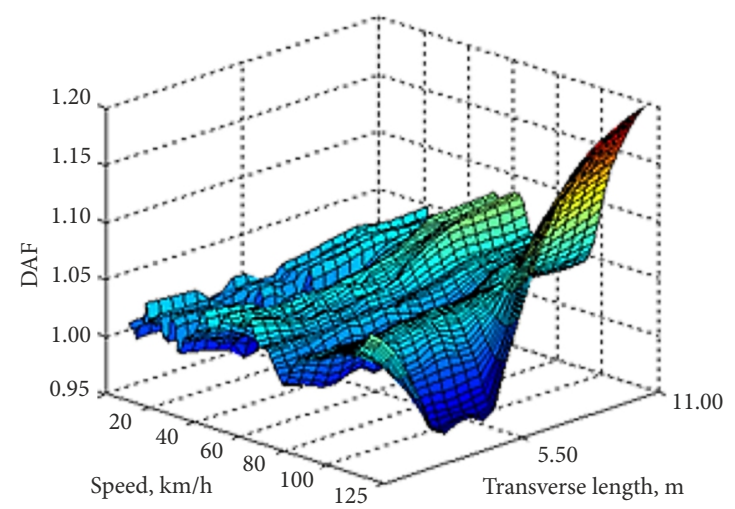

b) standard deviation

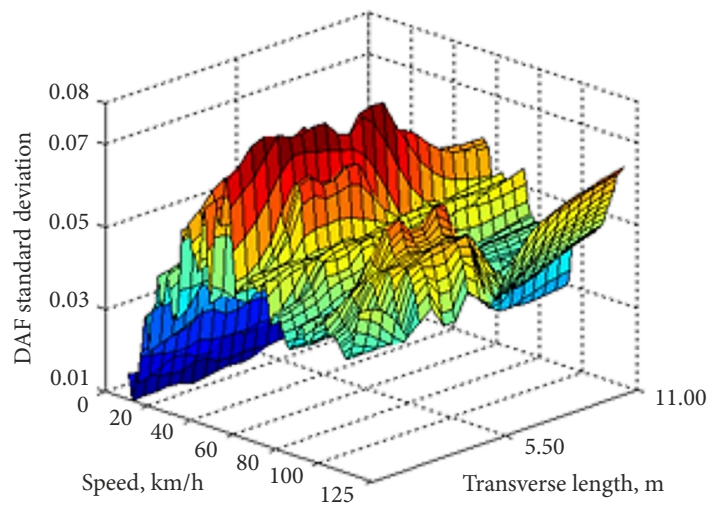

Figure 12. DAF-speed for plate model due to the 5-axle truck on class A profile

Figure 12 shows the results for the 5-axle truck defined in Section 1.2 moving on the same 15 class A profiles employed for the long vehicle. The highest mean DAF value is 1.2 (standard deviation 0.06 ) and corresponds to a total bending moment of $78.87 \mathrm{kNm}$ at node 1 for a vehicle speed of $122 \mathrm{~km} / \mathrm{h}$. A maximum total moment of $108.68 \mathrm{kNm}$ (for a speed of $98.28 \mathrm{~km} / \mathrm{h}$ ) is found for the position of the maximum static moment $(103.80 \mathrm{kNm})$, which is located at node 18 (Figure 10b) (DAF of 1.05 with a standard deviation of 0.052 ). The randomness of the road profiles has a more profound effect on the response to the 5-axle vehicle than on the response to the long vehicle. As a result, the standard deviation for the 5 -axle vehicle is larger than for the long vehicle, particularly at faster speeds.

Table 3 summarizes the highest DAF values obtained for the plate mid-span, the two vehicles, the two road classes and the fifteen road carpets per class. The table also gives for reference the DAF value with a 95\% Confidence Interval (CI). Cantero et al. (2011) published values of DAF for a $15 \mathrm{~m}$ bridge considerably smaller than those in Table 3. They focus on a distribution of speed based on WIM data of mean $85.47 \mathrm{~km} / \mathrm{h}$ and standard deviation $3.70 \mathrm{~km} / \mathrm{h}$ for 5 -axle trucks, and a distribution of mean $79.69 \mathrm{~km} / \mathrm{h}$ and standard deviation $5.67 \mathrm{~km} / \mathrm{h}$ for cranes. Therefore, they cover a narrower range of speeds that misses the critical speed for the crane.

\subsection{Influence of troughs located at the expansion joint on DAF}

This section combines troughs characterized by varying heights with the two road classes as described in Sec- tion 1.3.2. Then, the analysis carried out in Section 3.1.1 is repeated here for the resulting profiles. In the situation involving the long vehicle over a class A profile with troughs, the highest mean DAF turns out to be 1.19 with a standard deviation of 0.086 and takes place at node 1 for a total bending moment of $165.33 \mathrm{kNm}$ at the critical speed of $30.24 \mathrm{~km} / \mathrm{h}$. The highest static and total bending moments are $204.23 \mathrm{kNm}$ and $231.66 \mathrm{kNm}$ (for a speed of $29.16 \mathrm{~km} / \mathrm{h}$ ) respectively (DAF of 1.156 with a standard deviation of 0.046 ), both taking place at node 23 . In contrast to other transversal positions with the same speed $(30.24 \mathrm{~km} / \mathrm{h})$, lower DAFs of 1.103 and total bending moment, value of $220.06 \mathrm{kNm}$ is found for node 18 , which falls under the path of the right wheel. Similarly, a relatively low DAF of 1.108 and total bending moment of $203.39 \mathrm{kNm}$ is found at node 13 under the path of the left wheel. DAF figures are expected to experience an increase with the deterioration of the road profile and the pattern to become irregular; however, the DAF-speed pattern for class B road profiles combined with troughs still exhibits similar characteristics to the class A. The highest DAF value of 1.22 with standard deviation 0.07 takes place at node 1 with a maximum total bending moment of $169.78 \mathrm{kNm}$ at the critical speed of $30.24 \mathrm{~km} / \mathrm{h}$. The highest static and total bending moments are $204.23 \mathrm{kNm}$ and $236.27 \mathrm{kNm}$ (for a speed of $30.24 \mathrm{~km} / \mathrm{h}$ ) respectively and they take place at the same node 23 (DAF value of 1.156 with a standard deviation of 0.046).

In the case of the 5-axle truck over the bridge with a class A and troughs, a highest DAF of 1.22 with a standard deviation of 0.064 is found at node 1 (for a speed of $122 \mathrm{~km} / \mathrm{h}$ ). Furthermore, the highest static and total bend-

Table 3. Mean value $(\mu)$ and standard deviation $(\sigma)$ of DAF for road classes A and B (critical speed in $\mathrm{km} / \mathrm{h}$ )

\begin{tabular}{|l|c|c|c|c|c|c|c|c|}
\hline \multirow{3}{*}{ Vehicle Type } & \multicolumn{9}{|c|}{ Class type of road surface (without troughs) } \\
\cline { 2 - 10 } & \multicolumn{4}{|c|}{$\mathrm{A}$} & \multicolumn{4}{c|}{ B } \\
\cline { 2 - 10 } & $\mu$ & $\sigma$ & $95 \%$ CI & speed & $\mu$ & $\sigma$ & $95 \%$ CI & speed \\
\hline Long-vehicle & 1.13 & 0.044 & $1.107-1.152$ & 30.24 & 1.20 & 0.07 & $1.160-1.230$ & 30.24 \\
\hline 5-axle truck & 1.19 & 0.060 & $1.160-1.220$ & 122.00 & 1.20 & 0.12 & $1.139-1.260$ & 122.00 \\
\hline
\end{tabular}


Table 4. Mean value $(\mu)$ and standard deviation $(\sigma)$ of DAF for road classes A and B combined with troughs (critical speed in km/h)

\begin{tabular}{|l|c|c|c|c|c|c|c|c|}
\hline \multirow{3}{*}{ Vehicle Type } & \multicolumn{9}{|c|}{ Class of road surface (with troughs) } \\
\cline { 2 - 9 } & \multicolumn{9}{|c|}{ A } & \multicolumn{4}{c|}{ B } \\
\cline { 2 - 9 } & $\mu$ & $\sigma$ & $95 \%$ CI & Speed & $\mu$ & $\sigma$ & $95 \%$ CI & speed \\
\hline Long-vehicle & 1.19 & 0.086 & $1.146-1.233$ & 30.24 & 1.22 & 0.070 & $1.185-1.255$ & 30.24 \\
\hline 5-axle truck & 1.22 & 0.064 & $1.187-1.252$ & 122.00 & 1.23 & 0.125 & $1.166-1.293$ & 122.00 \\
\hline
\end{tabular}

ing moments are $103.80 \mathrm{kN}$ and $113.45 \mathrm{kNm}$ (at the speed of $44.28 \mathrm{~km} / \mathrm{h}$ ) respectively, and both take place at node 18 , leading to a mean DAF value of 1.093 with a standard deviation of 0.048 . Statistics of DAF values are summarized in Table 4 for the 30 carpets with troughs under investigation. The values of DAF in Table 4 are conservative because the highest DAFs are associated with regions with a comparatively small static moment, i.e., near the plate edge. Although DAF due to the long vehicle increases with rougher roads and troughs, DAF figures remain somewhat smaller than those corresponding to the 5-axle truck.

The model based on point loads of Section 2 helps to understand the underlying constructive and destructive interferences among axles as demonstrated by Figures 7 and 8 respectively and to identify the critical speed for a long vehicle as shown by Figure 10. However, the peak DAF at the critical speed by a point load model leads to a value that differs from the one obtained with sprung models. The latter is explained by the height of road irregularities, which have changes comparable to the bridge deflections, more significantly the rougher the road surface. These irregularities have a strong impact on vehicle dynamic forces and subsequently on the bridge response. Hence, Table 3 shows a mean DAF of 1.20 for the road class B population, which is higher than the value of 1.13 obtained for the road class A. Similarly, when a trough is added at the expansion joint, mean DAFs increase from 1.13 (Table 3) to 1.19 (Table 4) for a class A and from 1.20 (Table 3) to 1.22 (Table 4) for a class B. Point loads are unable to capture the effect of road roughness. The highest nodal DAF of 1.15 is obtained using the 38-point load model on a plate model for the long vehicle, which is $6.1 \%$ less than the DAF value of 1.22 obtained using the sprung model on a class B profile with troughs. However, the DAF value provided by the 38-point load model is only $1.8 \%$ higher than the mean value of 1.13 obtained by the sprung model on a class A profile without troughs. This shows that a simplistic point load model can be used for preliminary assessment of DAF for smooth road profiles. The 3D nature of the problem has to be considered, particularly in the case of the vehicle driving eccentrically with respect to the bridge centreline. It has been seen how an equivalent 19-point load model on a planar beam model provides a DAF value of 1.066 at the critical low speed (Figure 5), which is considerably less than the global DAF factor of 1.11 found for the 38-point loads on the plate model. In the case of a class A road profile, the beam model underestimates the highest nodal dynamic amplification of
1.13 (at node 1), although it is relatively close to the DAF associated to the maximum static moment (i.e., DAF = 1.087 at node 23 ).

\section{Conclusions}

Extremely long and heavy trucks need to have a traffic permit before travelling on the roads. The road authorities must carefully examine how particular truck configurations affect the safety of the bridges across the route decided for the vehicle. In the case of large forces generated by the truck being close to the loading capacity of certain bridges, the bridge response must be evaluated accurately, i.e., allowing for the dynamic increment resulting from the interaction between the vehicle and the bridges. Only then, the engineer will be in a position to take a precise decision on the permit. For two vehicle types and two road profile classes, this paper has provided an insight into the DAF of the mid-span bending moment of a $15 \mathrm{~m}$ long simply supported bridge. The bridge has been modelled as an isotropic thin plate. The analysis has covered the influence of road roughness, with and without damaged expansion joints, and the configuration, transverse location and speed of the vehicle on DAF. The results have indicated that:

1. A considerable amplification of the dynamic response takes place for a long vehicle comprised of evenly spaced axles travelling at a low speed of $30.24 \mathrm{~km} / \mathrm{h}$. This finding appears to be counterintuitive given the large gross vehicle weight, long rigid configuration, and low speed. However, when the recurrence of equally spaced axles at a critical low speed synchronizes with the primary period of the vibration of the bridge, the response waves produced by each wheel force add together causing a resonance effect. The critical speed is calculated from the axle spacing in the vehicle and the main frequency of the vibration of the bridge.

2. When the critical speed is unavoidable, a dynamic allowance must be added to static calculations of the bridge response (i.e., via the application of a DAF) before granting a permit to long heavy vehicles comprised of evenly spaced axles. The shape of the DAF-speed pattern is brought about by utilizing a simple model based on point loads. The variability of these patterns increases with the worsening of the road condition and the introduction of troughs (i.e., larger mean DAFs and larger standard deviations 
the poorer the road condition). The impact of road roughness on DAF is shown to be less important for the long vehicle than for a 5 -axle vehicle.

Even though this paper has focused on a specific vehicle and bridge, the conclusions are applicable to other scenarios, i.e., similarly to the phenomenon investigated here, loads by several trucks driving at equal distances will be sensitive to critical speeds related to the bridge frequency. This scenario is found in a convoy where similar truck configurations travel at a uniform speed with a similar headway. Therefore, the findings in this paper have the potential to be extended to future developments in the field of electronic tow bars for convoys.

\section{References}

AASHTO. (2012). LRFD bridge design specifications, Washington, DC. American Association of State Highway Officials (AASHO). (1962). “The AASHO road test.” Rep. 4, Special Rep. 61D, Highway Research Board, Washington, DC.

Brady, S. P., \& O’Brien, E. J. (2006). Effect of vehicle velocity on the dynamic amplification of two vehicles crossing a simply supported bridge. Journal of Bridge Engineering, 11(2), 250-256. https://doi.org/10.1061/(ASCE)1084-0702(2006)11:2(250)

Brady, S. P., O’Brien, E. J., \& Žnidarič, A. (2006). Effect of vehicle velocity on the dynamic amplification of a vehicle crossing a simply supported bridge. Journal of Bridge Engineering, 11(2), 241-249. https://doi.org/10.1061/(ASCE)1084-0702(2006)11:2(241)

Cantero, D., O’Brien, E. J., \& González, A. (2010). Modelling the vehicle in vehicle-infrastructure dynamic interaction studies. Proceedings of the Institution of Mechanical Engineers, Part K: Journal of Multi-Body Dynamics, 224(2), 243-248. https://doi.org/10.1243/14644193JMBD228

Cantero, D., González, A., \& O’Brien, E. J. (2011). Comparison of bridge dynamic amplification due to articulated 5-Axle trucks and large cranes. Baltic Journal of Road and Bridge Engineering, 6(1), 39-47. https://doi.org/10.3846/bjrbe.2011.06

Cantero, D., Arvidsson, T., O’Brien, E. J., \& Karoumi, R. (2015). Train-track-bridge modelling and review of parameters. Structure and Infrastructure Engineering, 12(9), 1051-1064. https://doi.org/10.1080/15732479.2015.1076854

Cantero, D., \& Karoumi, R. (2016). Numerical evaluation of the mid-span assumption in the calculation of total load effects in railway bridges. Engineering Structures, 107, 1-8. https://doi.org/10.1016/j.engstruct.2015.11.005

Casas, J. R., \& Aparicio, A. C. (2001). Computer-based bridge management system for permit vehicle routing. ComputerAided Civil and Infrastrcuture Engineering, 16(6), 444-454. https://doi.org/10.1111/0885-9507.00246

Correia, J. P. R. R., \& Branco, F. A. B. B. (2006). New methodology: permit checking of vehicular overloads. Journal of Bridge Engineering, 11(3), 274-281. https://doi.org/10.1061/(ASCE)1084-0702(2006)11:3(274)

Cebon, D. (1999). Handbook of vehicle-road interaction (600 p.). Swets \& Zeitlinger Lisse, The Netherlands.

Cebon, D., \& Newland, D. E. (1983). Artificial generation of road surface topography by the inverse FFT method. Vehicle System Dynamics, 12(1-3), 160-165. https://doi.org/10.1080/00423118308968747

Deng, L., Yu, Y., Zou, Q., \& Cai, C. S. (2014). State-of-the-Art review of dynamic impact factors of highway bridges. Journal of Bridge Engineering, 20(5), 1-14. https://doi.org/10.1061/(ASCE)BE.1943-5592.0000672
Ding, L., Hao, H., \& Zhu, X. (2009). Evaluation of dynamic vehicle axle loads on bridges with different surface conditions. Journal of Sound and Vibration, 323(3-5), 826-848. https://doi.org/10.1016/j.jsv.2009.01.051

Enright, B., \& O’Brien, E. J. (2013). Monte Carlo simulation of extreme traffic loading on short and medium span bridges. Structure and Infrastructure Engineering, 9(12), 1267-1282. https://doi.org/10.1080/15732479.2012.688753

Fafard, M., Bennur, M., \& Savard, M. (1997). A general multiaxle vehicle model to study the bridge-vehicle interaction. Engineering Computations, 14(5), 491-508. https://doi.org/10.1108/02644409710170339

Fu, T. T., \& Cebon, D. (2002). Analysis of a truck suspension database. International Journal of Heavy Vehicle Systems, 9(4), 281-297. https://doi.org/10.1504/IJHVS.2002.001180

González, A. (2010). Vehicle-bridge dynamic interaction using finite element modelling. In D. Moratal (Ed.), Finite Element Analysis, Sciyo, Croatia (pp. 637-662).

https://doi.org/10.5772/10235

González, A., O’Brien, E. J., Cantero, D., Li, Y., Dowling, J., \& Žnidarič, A. (2010). Critical speed for the dynamics of truck events on bridges with a smooth road surface. Journal of Sound and Vibration, 329(11), 2127-2146.

https://doi.org/10.1016/j.jsv.2010.01.002

González, A., Rowley, C., \& O’Brien, E. J. (2008ª). A general solution to the identification of moving vehicle forces on a bridge. International Journal for Numerical Methods in Engineering, 75(3), 335-354. https://doi.org/10.1002/nme.2262

González, A., Rattigan, P., O’Brien, E. J., \& Caprani, C. (2008b). Determination of bridge lifetime dynamic amplification factor using finite element analysis of critical loading scenarios. Engineering Structures, 30, 2330-2337.

https://doi.org/10.1016/j.engstruct.2008.01.017

Harris, N. K., O’Brien, E. J., \& González, A. (2007). Reduction of bridge dynamic amplification through adjustment of vehicle suspension damping. Journal of Sound and Vibration, 302(3), 471-485. https://doi.org/10.1016/j.jsv.2006.11.020

Honda, H., Kajikawa, Y., \& Kobori, T. (1982). Roughness characteristics at expansion joint on highway bridges. Proceedings of Japan Society of Civil Engineers, 324, 173-176. https://doi.org/10.2208/jscej1969.1982.324_173

ISO 8608:1995 Mechanical Vibration-Road Roughness Surfaces.

Kim, C.-W., Kawatani, M., \& Kwon, Y.-R. (2007). Impact coefficient of reinforced concrete slab on a steel girder bridge. Engineering Structures, 29(4), 576-590.

https://doi.org/10.1016/j.engstruct.2006.05.021

Kirkegaard, P. H., Nielsen, S. R. K., \& Enevoldsen, I. (1997). Heavy vehicles on minor highway bridges - dynamic modelling of vehicles and bridges (44 p.). Aalborg University, Instituttet for Bygningsteknik.

Kwasniewski, L., Wekezer, J., Roufa, G., Li, H., Ducher, J., \& Malachowski, J. (2006). Experimental evaluation of dynamic effects for a selected highway bridge. Journal of Performance of Constructed Facilities, 20(3), 253-260. https://doi.org/10.1061/(ASCE)0887-3828(2006)20:3(253)

Lehtonen, T., Kaijalainen, O., Pirjola, H., \& Juhala, M. (2006). Measuring stiffness and damping properties of heavy dynamics tyres. Proceedings of the FISITA World Automotive Congress, October 22-27, 2006. Yokohama, Japan.

Li, H. (2005). Dynamic response of highway bridges subjected to heavy vehicles (146 p.). PhD Dissertation, Florida state University. Retrieved from http://etd.lib.fsu.edu/theses/available/ etd-11092005-171029/. 
Li, J., \& Su, M. (1999). The resonant vibration for simply supported girder bridge under high-speed trains. Journal of Sound and Vibration, 224(5), 897-915. https://doi.org/10.1006/jsvi.1999.2226

Moghimi, H., \& Ronagh, H. R. (2008). Impact factors for a composite steel bridge using non-linear dynamic simulation. International Journal of Impact Engineering, 35(11), 1228-1243. https://doi.org/10.1016/j.ijimpeng.2007.07.003

Mohammed, O., Cantero, D., González, A., \& Al-Sabah, S. (2014). Dynamic amplification factor of continuous versus simply supported bridges due to the action of a moving load. Proceedings of Civil Engineering Research in Ireland, August 28-29, 2014. Belfast, UK. Retrieved from http://researchrepository.ucd.ie/handle/10197/6582.

Mohammed, O., \& González, A. (2017). Static and dynamic moments for any plane within a straight solid slab bridge caused by the crossing of a truck. Engineering Structures, 150, 465480. https://doi.org/10.1016/j.engstruct.2017.07.059

O’Brien, E. J., Keogh, D., \& O'Connor, A. (2014). Bridge deck analysis ( $2^{\text {nd }}$ ed.) CRC Press. Retrieved from https://www. crcpress.com/Bridge-Deck-Analysis-Second-Edition/ObrienKeogh-OConnor/p/book/9781482227239

Reddy, J. N. (2002). Energy principles and variational methods in applied mechanics. John Wiley \& Sons. Retrieved fromhttps://books.google.com/books?hl=en\&lr=\&id=3gw5rxLQd aQC\&pgis $=1$.
Rezaiguia, A., Ouelaa, N., Laefer, D. F., \& Guenfoud, S. (2015). Dynamic amplification of a multi-span, continuous orthotropic bridge deck under vehicular movement. Engineering Structures, 100, 718-730. https://doi.org/10.1016/j.engstruct.2015.06.044

Rowley, C., O’Brien, E., González, A., \& Znidaric, A. (2009). Experimental testing of a moving force identification bridge weigh-in-motion algorithm. Experimental Mechanics, 49(5), 743-746. https://doi.org/10.1007/s11340-008-9188-3

Sayers, M. W., \& Karamihas, S. M. (1996). Interpretation of Road Roughness Profile Data - Final Report. University of Michigan Transportation Research Institute (UMTRI).

Shi, X., Cai, C. S., \& Chen, S. (2008). Vehicle induced dynamic behavior of short-span slab bridges considering effect of approach slab condition. Journal of Bridge Engineering, 13(1), 8392. https://doi.org/10.1061/(ASCE)1084-0702(2008)13:1(83)

Vigh, A., \& Kollár, L. P. (2007). Routing and permitting techniques of overweight vehicles. Journal of Bridge Engineering, 12(6), 774-784. https://doi.org/10.1061/(ASCE)1084-0702(2007)12:6(774)

Yang, Y. B., Yau, J. D., \& Wu. Y. S. (2004). Vehicle Bridge Interaction Dynamics with Application to High-Speed Railways (564 p.). World Scientific Publishing Co. Pte. Ltd.

Wong, J. Y. (2008). Theory of ground vehicles (592 p.). John Wiley \& Sons, New York. 